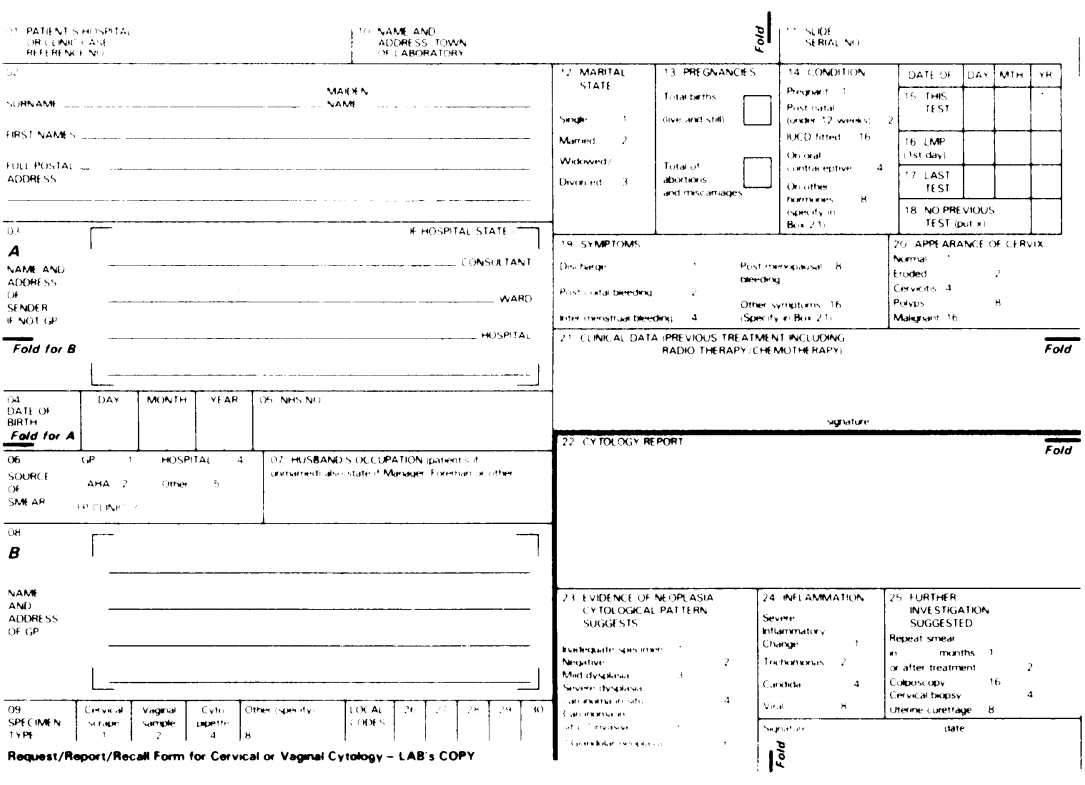

FIG 2-Request form for cervical cytology currently in use

boxes which are the same on the old and the revised forms have changed their numbers. In fact, 21 boxes have had changes of number, but, worse still, in many of the categories in the boxes the numbers have changed. These changes are disastrous for laboratories which use these numbers on computer systems. Fortunately, existing report codes of cytological pattern have been retained, but all the source codes except GP have been shuffled around and the codes under the new 19 ("condition"), 23 ("specific infection"), and 24 ("management suggested") boxes, which previously allowed summation entries, have been changed. In Northampton our cytology computer holds 181000 test records and if data are now collected on the revised form they will be highly incompatible with our existing data. Reprogramming to recode our existing data would be expensive and might not work. Our data entry screens are set up in the order of the old form, but in the revised form some sequences have been changed. For instance, "source of smear" comes after, not before, the "name and address of GP," and for us this will slow down the entry of data.

On the reverse of every revised form will be printed details on taking a cervical smear. This is unnecessary and will cause difficulties to laboratories that use the blank reverse of the old form as a note pad for checking, rescreening, quality control, and general education in cytology.

\section{Conclusion}

We are firmly of the opinion that this revised request/report form must be amended before it can be regarded as acceptable for use. If the serious faults that we have pointed out are not corrected we think that many laboratories with a substantial investment in computerisation will be obliged to produce their own cytology request forms. This would be a retrograde step.

\title{
A mobile surgery for single homeless people in London
}

\author{
S S Ramsden, P Nyiri, J Bridgewater, D J El-Kabir
}

\begin{abstract}
Little is known about the social and medical characteristics of people who regularly sleep rough, or whether medical care can be targeted at these people. In 1987 a mobile surgery was used to provide primary health care at two sites in central London where many single homeless people sleep outdoors. One hundred and forty six patients were seen with illnesses ranging from scabies to osteomyelitis and tuberculosis. Sociodemographic data showed the patients to be generally an isolated group with deprived and unstable backgrounds, often compounded by alcohol abuse. Over a third of the patients from one site attended a drop in surgery for homeless people in Soho within a month after seeing a doctor in the mobile surgery. This suggests that the project can be a first step in integrating this isolated group with health care facilities.
\end{abstract}

\section{Wytham Hall Sick Bay,} London W9 20J

S S Ramsden, MRCP, resident medical officer

P Nyiri, BA, medical student $\mathrm{J}$ Bridgewater, $\mathrm{MB}$, resident medical officer

\section{Great Chapel Street} Medical Centre, London W1 7AL

D J El-Kabir, DM, physician in charge

Correspondence to: Dr Ramsden. hostels have brought health care to this deprived group. ${ }^{367}$ Less is known about those who regularly "sleep rough" largely because they are so difficult to reach, but surveys suggest that these people suffer much physical and psychiatric illness as well as frequent alcohol abuse. ${ }^{389}$

In 1987, after a grant from the London-Edinburgh Trust, we bought a Renault Master van converted into a mobile surgery to provide primary health care at the sites where those sleeping rough congregate. The aims of this study were twofold: firstly, to investigate the social and medical characteristics of the patients sleeping rough in central London, and, secondly, to assess the acceptability and outcome of a mobile surgery for such patients.

\section{Methods}

The sites-We restricted ourselves to two sites in inner London where homeless people congregate: Lincoln's Inn Field and the Bullring. Lincoln's Inn Field is a small park in central London. Up to 50 single homeless people sleep there every night. The Bullring is a grim area of interconnecting concrete subways on the south bank of the Thames. Up to 150 people sleep there each night.

The mobile surgery and its operation-The mobile surgery was run by a doctor and two other people, either medical students or health workers for homeless people. Each site was visited once a week. We had to show respect and patience to be accepted. Some patients would take weeks before feeling that they could see the doctor. As far as possible most conditions 
TABLE I-Sociodemographic data for homeless people in London and attending mobile surgery unit

No of patients

\begin{tabular}{lc}
\hline Duration of sleeping rough $(n=136)$ \\
<1 Month & 34 \\
1 Month- & 40 \\
6 Months- & 11 \\
PI2 Months & 48 \\
Unknown & 3 \\
\multicolumn{1}{c}{$\quad$ Marital state $(n=146)$} \\
Single & 71 \\
Divorced & 27 \\
Separated & 26 \\
Married & 6 \\
Widower & 4 \\
Unknown & 12 \\
& \\
South of England & 52 \\
Scotland & 33 \\
North of England & 27 \\
Ireland & 21 \\
Midlands & 7 \\
Wales & 4 \\
Other & 1 \\
Unknown & 1 \\
&
\end{tabular}

TABLE II - Frequency and type of condition presenting among 146 homeless people in London

Type of
condition No of patients

Musculoskeletal $\quad 45$

Respiratory

Respiratory

Skin

Alcohol rela

Infestation

Digestive

Central nervous system

Cardiovascula

Psychiatric

Drug addiction

Obstetric

Ophthalmic

Ear, nose, and throat

Genitourinary

Chiropody

Dental

45
40
20
16
13
13
10
7
6
5
3
3
2
2
1
1

TABLE III-Use of alcohol and illegal drugs by 146 homeless people in London

No of patients

\begin{tabular}{lr}
\multicolumn{2}{c}{$\begin{array}{c}\text { Mean alcohol consumption over } \\
\text { previous month }\end{array}$} \\
None & 31 \\
<8 Units/day & 34 \\
8-16 Units/day & 19 \\
>16 Units/day & 50 \\
Unknown & 12 \\
\multicolumn{2}{c}{ Illegal use of drugs } \\
In past month & 17 \\
In past & 20 \\
No history & 104 \\
Unknown & 5
\end{tabular}

were dealt with in the surgery. If necessary patients were referred to Great Chapel Street Medical Centre or other primary medical care facilities. Two injured patients were taken directly to a casualty department. Some acutely ill patients were admitted to our sick bay for homeless men (if they agreed). A supply of medicines and dressings was taken to start treatment, and patients were encouraged, when appropriate, to attend more formal primary care centres to continue their treatment.

Collection of data and its validity-A standard questionnaire designed for the study was used. All patients gave consent and were assured of confidentiality. The accuracy of data could not in many cases be validated, but we believe the data to be generally reliable for four reasons. (1) Patients were almost always keen to help the doctor; no one refused to answer. (2) Sociodemographic data were routinely collected on patients at our medical centre and sick bay, which allowed us to check the reproducibility of data in those seen there. The data proved to be highly consistent. (3) Short birth certificates were applied for for nine of the 10 patients admitted to the sick bay (one was born in Hungary) for claims for social security. In seven of the nine cases the date and town of birth were validated as correct. Two were untraceable and may have been false. (4) Patients were interviewed after seeing the doctor. Shanks showed that the consistency of data obtained by someone with a rapport with homeless people is much greater than that obtained by a more impersonal "research worker.",

\section{Results}

The period of study at Lincoln's Inn Field was from October 1987 to June 1988. Sixty one new patients were seen and 121 consultations made. The surgery began operating at the Bullring in June 1988, and data were recorded for three months. Eighty five new patients were seen and 123 consultations carried out. The data from the two sites were highly similar and were combined for the purposes of the study.

\section{SOCIODEMOGRAPHIC DATA}

The patients' mean age was 39.9 (range 16 to 64 ) years. Only 13 of the 146 patients were women. One hundred and thirty six patients were sleeping rough at the time of interview, five were in squats, three were in hostels, and two were staying with friends. All were white. Table I shows the duration of sleeping rough at the time of interview, marital state, and origin of the patients.

The mean age at leaving school was 15 (range 12 to 19). No one had received higher education. Only four patients, had had employment with a social class grading of 1 or 2 . Eight patients had parents of social class 1 or 2 (information was lacking on 25 patients). Ninety five patients were receiving social security benefits, 17 had casual jobs, and 20 claimed to have no income (some begged and others survived on handouts). Three were receiving pensions, and information was lacking on 11 others. Forty nine claimed never (or rarely) to use hostels or day centres for the homeless.

\section{MEDICAL DATA}

Table II shows the frequency and types of presenting condition. A breakdown of the diagnoses gives an indication of the illnesses suffered. Musculoskeletal disorders were most common, and a third were directly attributable to trauma. This included six cases of laceration and five of blunt injury (with or without fracture), usually due to fighting or falls while drunk. The other musculoskeletal disorders were due to muscle strains (17 cases), osteoarthritis (11), tendinitis (three), and osteomyelitis (two, one of which was certainly active), and congenital deformity (one). The respiratory disorders were largely acute bronchitis (15) and asthma and chronic airways disease (11) Five patients had tuberculosis; the disease had been diagnosed previously and they were still being treated, though compliance with treatment was poor. The principal dermatological diagnoses were tinea pedis ( six cases) and eczema or psoriasis (six). All of the patients with conditions related to alcohol abused alcohol and were requesting detoxification or vitamins. Infestations comprised scabies and pediculosis.

The principal gastrointestinal diagnoses were peptic ulcers and gastritis (five) and haemorrhoids (four). Central nervous system disease was mostly epilepsy (eight), which was often poorly controlled. Cardiovascular disorders comprised ischaemic heart disease (five) and varicose veins (two). The psychiatric diagnoses were psychosis and depression. Five patients consulted about their drug addiction. Three pregnant women were seen, and attempts were made to arrange housing and antenatal care.

Fifty four patients had a general practitioner in London but 90 did not (two unknown). Patients at Lincoln's Inn Fields were asked why they had no general practitioner. Of the 27 without one, 22 gave the main reason as not needing one, and only two gave their reason as feeling that general practitioners were unhelpful to the homeless. Table III shows use of alcohol and illegal drugs by the patients.

\section{Discussion}

The sociodemographic features of the patients, (predominantly white men, many from Scotland and Ireland, and frequently from poor backgrounds) were consistent with those in other studies of single homeless people in England. ${ }^{9112}$ The high prevalence of divorce, separation, or never having married along with coming from a broken home and being brought up in an orphanage, shown by Edwards et $a l,{ }^{9}$ is part of a picture of social and emotional deprivation and instability from early life. Although homeless people lack close one to one ties, as evidenced by their marital state, those we met were, none the less, mutually supportive; some would rather we saw their friends than themselves despite their own need. One important finding was that a third hardly ever used day centres or hostels and clearly would not benefit from efforts to improve health care of the homeless based solely in such centres. It is this group of socially isolated patients who have most to gain from an outreach programme such as the mobile surgery.

The medical problems we encountered were those commonly seen among homeless people, with a preponderance of respiratory, musculoskeletal, and alcohol related illnesses. ${ }^{131314}$ Also common were infestations, which, surprisingly, proved treatable as patients knew where to bathe and change their clothes. Some patients were seriously unwell; two had discharging osteomyelitis, one of whom could not be treated by us or hospitals as his "voices" always told him to move on. Few patients were actively psychotic when seen, though many had a history of psychiatric illness. Forensic and psychiatric histories were not documented as patients were often suspicious of such questions. Other studies have shown the high prevalence of these problems among homeless people. ${ }^{8911}$

Sixty one per cent of the patients had no general practitioner in London, and most with a general practitioner had not consulted for the presenting medical problem. The reasons underlying this are complex but important. Some found waiting rooms and appointment systems difficult to cope with. Some 
claimed that general practitioners were unhelpful to homeless patients, though this was not a major reason among the patients we studied. Others may have been too drunk or had other claims on their time such as obtaining social security benefits in preference to medical care. There were, however, often deeper reasons. One patient saw us three or four times before consulting for a chronic condition. When asked why he and his friends were so reluctant he answered, "Because we're afraid of what you might find."'

Serious alcohol abuse was an important finding, and of the $21 \%$ who had not drunk over the past month, many were "dry alcoholics," though the rest were teetotal. As in the study of Edwards et al illegal use of drugs was not a prominent feature of our patients. Only a few thought that drugs had much to offer (in contrast to alcohol), and many were surprised to be even asked whether they used drugs.

The mobile surgery was quickly accepted, and many hesitant patients had their medical complaints attended to. On this basis alone the project was successful. Perhaps of greater importance was that a third of patients seen at Lincoln's Inn Field subsequently attended our nearby drop in medical centre to continue their medical care. This suggests that a mobile surgery can act as a link between those sleeping rough and formal medical services. In addition, patients admitted to our sick bay also fared well with four out of 10 staying in permanent housing after discharge. We found that, given the opportunity, some patients were able to make responsible decisions concerning their health and housing that had previously seemed impossible. We know that some of those sleeping rough would not see us despite being ill. The surgery is not a panacea for all homeless people sleeping rough, but it can make an important difference to the health and wellbeing of many who have had few chances in their lives.

We thank the members of Wytham Hall Sick Bay for their help in running the mobile surgery and D R El Kabir for help in compiling this paper.

1 Scott R, Gaskell PG, Morrel DC. Patients who reside in common lodging houses. Br Med F 1966; ii: 1561-4.

2 Brickner PW, Scanlan BC, Conanan B, et al. Homeless persons and health care. Ann Intern Med 1986;104:405-9.

3 Hewetson J. Homeless people as an at-risk group. Proc R Soc Med 1975;68: 9-13.

4 Laidlaw SAI. Glasgow common lodging houses and the people who live in them. Glasgow: Glasgow Corporation, 1956

5 Alstrom $\mathrm{CH}$, Lindelius R, Salum I. Mortality among homeless men. $\mathrm{Br} \mathcal{F}$ Addict 1975:70:242-52.

6 El-Kabir DJ. Great Chapel Street medical centre. Br Med f 1982;284:480-1.

7 Shanks N. Medical care of the homeless. Br Med $\mathcal{F}$ 1982;284:1679.

8 Weller BGA, Weller MPI, Coker E, Mahamed S. Crisis at Christmas. Lance 1987;i:553-4.

9 Edwards G, Hawker A, Williamson V, Hensman C. London's skid row. Lance $1966 ; \mathrm{i}: 249-52$

10 Shanks N. Consistency of data collected from inmates of a common lodging house. I Epidemiol Community Health 1981;35:133-5.

11 Lodge-Patch IC. Homeless men in London. 1. Demographic findings in a lodging house sample. Br f Psychiatry 1971;118:313-7.

12 Shanks N. Medical provision for the homeless in Manchester. $f(R$ Coll Gen Pract 1983;33:40-3.

13 Toon PD, Thomas K, Doherty M. Audit of work at a medical centre for the homeless over one year. IR Coll Gen Pract 1987;37:120-2.

14 Ramsden SS, Baur S, El-Kabir DJ. Tuberculosis among the central London single homeless: a four year retrospective study. $\exists R$ Coll Physicians Lond 1988;22:16-7.

(Accepted 1 December 1988)

\section{BOOKS RECEIVED}

Accident and emergency

Pocket Reference. "Accidents and Emergencies." N G Kirby. (Pp xvi+ 442; figs; £16 paperback.) Tunbridge Wells: Castle House Publications, 1988. ISBN 0-7194-0111-9.

Addiction

Drugs and Drug Using: a Guide for AIDS Workers. Institute for the Study of Drug Dependence. ( $\mathrm{Pp}$ vi +38 , $£ 1.75$ including postage, paperback. Available from ISDD, Publications Sales, 1 Hatton Place, London ECIN 8ND. 1988. ISBN 0-948830-40-9.

\section{Allergy}

Progress in Allergy. Vol 44. "Arachidonate Metabolism in Immunologic Systems." Ed L Levine. Series editor K Ishizaka, P Kallos, P J Lachmann, B H Waksman. (Pp viii+216; figs; B H Waksman. (Pp vilit+216; fig 667.30.) Basel: Karger, 1988. Distrbuted by John Wail

\section{Alternative medicine}

Minding the Body, Mending the Mind. J Borysenko, with L Rothstein. (P xiv +241 ; figs; $£ 3.95$ paperback. Toronto: Bantam Books, 1988. ISBN 0-553-17514-9.

Neal's Yard Natural Remedies. Curtis, R Fraser, I Kohler. (Pp xxi 182 ; 55.99 paperback.) London: Arkana, 1988. Distributed by Penguin. ISBN 0-14-019000-7.

\section{Anaesthesia}

Lectures in Anaesthesiologv 1988. No 1 Editor in chief J S M Zorab. (Pp vit 102; figs; $£ 10$ paperback.) Oxford Blackwell Scientific, 1988. ISBN 0-632-02217-5.

Biology

drances in Membrane Fluidity. Vol 1 "Methods for Studying Membrane
Fluidity." Ed R C Aloia, C C Curtain, L M Gordon. Series editor R C Aloia. (Pp x+327; figs; \$120.) New York Liss, 1988. Distributed by John Wile and Sons. ISBN 0-8451-4600-9.

\section{Ear, nose, and throat}

Diseases of the Ear: Clinical and Pathologic Aspects. M Hawke, A F Jahn. (Pp $\mathrm{xi}+311$; colour plates; index; $£ 80$ Philadelphia: Lippincot/New York: Gower Medical, 1988. ISBN 0-397. 44673-X.

MCQs in Otolaryngology and Head and Neck Surgery. J M Lancer, A S Jones. (Pp ii +162; $\{9.95$ paperback.) London: Butterworth, 1988. ISBN 0-407-00761-X.

\section{Respiratory medicine}

Practical Clinical Medicine. "Asthma." Ed G Jariwalla. Series editors J Fry, G Sandler. (Pp 216; figs; £25.) Lancaster: MTP Press, 1988. ISBN 0-85200672-1.

\section{Rheumatology}

Immunopathogenetic Mechanisms of Arthritis. Ed J A Goodacre, W Carson Dick. (Pp x+252; figs; £45.) Lancaster: MTP Press, 1988. ISBN 0-85200 980-1.

Rheumatoid Arthritis: an Illustrated Guide to Pathology, Diagnosis, and Guide to Pathology, Diagnosis, and
Management. H R Schumacher, E P Management. H R Schumacher, E P
Gall. (Pp 420; figs and colour plates; Gall. (Pp 420; figs and colour plates; York: Gower Medical Publishing, York: Gower Medical Pu
1988. ISBN 0-397-44653-5.

The Road Back. Rheumatoid Arthritis. Its Cause and Its Treatment. T M Brown H Scammell (Pp 224; f11 95.) London: Macmillan, 1988. ISBN 0333-47516-X.

Sexual disorders

Advances in Clinical Andrology. Ed C L R Barratt, I D Cooke. (Pp 128; figs;
£25.) Lancaster: MTP Press, 1988. ISBN 0-7462-0034-X.

\section{Sports medicine}

Resource Manual for Guidelines for Exercise Testing and Prescription. American College of Sports Medicine. Ed S N Blair, P Painter, R R Padicine. Pp 464; figs; 134.37 . Philate, el al. Pp 464; figs; £34.37.) Philadelphia $1109-5$.

\section{Surgery}

Pocket Guide to the Operating Room. M A Goldman. (Pp xix $+599 ; \$ 27.50$ paperback.) Philadelphia: Davis, 1988. ISBN 0-8036-4174-5.

Recent Advances in Surgery. No 13. Ed R C G Russell. (Pp viii + 318; figs; \&17.50 paperback.) Edinburgh: Churchill Livingstone, 1988. ISBN 0443-039448.

Surgery of the Oesophagus. Ed G G Jamieson. (Pp 952; figs; £135.) Edinburgh: Churchill Livingstone, 1988. ISBN 0-443-03409-5.

Trauma Surgery. Ed J A Moylan. (P 08; figs; £71.75.) Philadelphia: Lippincott, 1988. Distributed by Harper and Row. ISBN 0-39750723-2.

\section{Surgery - transplantation}

Kidney Transplantation. L H ToledoPereyra. (Pp 428; figs; \$91.25.) Phila delphia: Davis, 1988. ISBN 0-8036 8504-1.

Pancreas Transplantation. L H ToledoPereyra. (Pp xiv +298; figs; $£ 80.25$.) Boston: Kluwer, 1988. ISBN 0-89838$369-2$

\section{Toxicology}

Macmillan Dictionary of Toxicology. E Hodgson, R B Mailman, J Chambers. (Pp 416; $£ 39.50$.) London: Macmillan, 1988. ISBN 0.333 39064-4.
Ultrasonics

Cardiac Doppler Ultrasound: a Clinical Perspective. A B Houston, I A Simpson. (Pp 164; figs; £35.) London: Wright, 1988. Distributed by Butterworth. ISBN 0-723-60995-0.

Practical Ultrasound. Ed R A Lerski. Pp 256; figs; $£ 25$ paperback.) Oxford: IRL Press, 1988. ISBN 1-85221157-1.

\section{Urology}

Difficult Diagnoses in Urology. Ed D L McCullough. (Pp 376; figs; £45.) New York: Churchill Livingstone, 1988. ISBN 0-443-08489-0.

Genitourinary Trauma. Ed A SCass. ( $\mathrm{Pp}$ 312; figs; £45.) Boston: Blackwell Scientific, 1988. ISBN 0-86542-040-8.

\section{Vascular surgery}

The Basic Science of Vascular Surgery. Ed J M Giordano, H H Trout, R G De Palma. (Pp 792; figs; \$89.) New York: Futura, 1988. ISBN 0-87993-321-6.

\section{Virology}

Monographs in Virology. Vol 17 "Human Monkeypox." Z Ježek, F Fenner. Series editor J L Melnick. (Pp $x+140$; figs; $£ 56.90$.) Basel: Karger 1988. Distributed by John Wiley and Sons. ISBN 3-8055-4818-4.

\section{Miscellaneous}

Developments in Veterinary Virology. "Newcastle Disease. Ed D J Alexander. Series editor Y Becker. $(\mathrm{PP}$ xi+378; figs; $\{71.25$.) Boston: Kluwer, 1988. ISBN 0-89838-392-7.

Developments in Veterinary Virology. "Rabies." Ed J B Campbell, K M Charlton. Series editor Y Becker. (Pp xii +431; figs; £79.50.) Boston: Kluwer, 1988. ISBN 0-89838-390-0. Lyn Marshall's Instant Stress Cure: Im-

mediate Relief from Everyday Stress Problems. L Marshall. (Pp 120; figs; f6.95 paperback.) London: Century Hutchinson, 1988. ISBN 0-71260215-1.

The Natural History of Disease. J A Ryle. (Pp xxiv +427 ; £50.) London: Keynes Press, 1988. ISBN 0-72790244-X.

A Natural History of Everyday Life. A Biographical Guide for Would-be Doctors of Society. Lord Taylor of Harlow. (Pp viii $+463+$ index; figs; $\{19.95$, BMA members $f 18.95$.) London: British Medical Journal London: 1988. ISBN 0-7279-0242-3.

Portraits from Memory. James Howie. (Pp x + 156+index; figs; $£ 14.95, \mathrm{BMA}$ members £13.95.) London: British Medical Journal/Memoir Club, 1988. ISBN 0-7279-0243-1.

Portraits, Paintings and Sculptures. A Sakula. (Pp xiii+194; colour plates; f20.) London: Royal Society of Medicine, 1988. ISBN 0-905958-71-3.

Profession of Medicine: a Study of the Sociology of Applied Knowledge. Reprint. E Freidson. (Pp 440; 511 95 